\title{
Stimulation of Pituitary-Adrenocortical System by Ginseng Saponin
}

\author{
Susumu HIAI, Hiroomi YOKOYAMA, \\ Hikokichi OURA aNd SABURo YANO* \\ Department of Biochemistry, Research Institute for WAKAN-YAKU, \\ Toyama University, Gofuku, Toyama 930 and *Department of \\ Internal Medicine, Toyama Medical and Pharmaceutical \\ University, Sugitani, Toyama 930-01, Japan
}

\begin{abstract}
Synopsis
Effects of preparations of saponin mixture and isolated ginsenosides, extracted from the root of Panax ginseng, on plasma corticotropin (ACTH) and corticosterone concentrations in rats were determined by the radioimmunoassay and competitive protein binding method. When ginseng saponin mixture was administered to rats intraperitoneally, plasma ACTH and corticosterone increased significantly 30,60 and 90 min after the treatment. The kinetic pattern of the increase in plasma ACTH was almost parallel to that in plasma corticosterone. Isolated ginsenoside, protopanaxadiol or protopanaxatriol glycoside, also increased plasma corticosterone. The ginseng-induced increase in plasma corticosterone was suppressed by pretreatment with dexamethasone. Thus the ginseng saponin was found to act on the hypothalamus and/or hypophysis primarily, and stimulated ACTH secretion which resulted in increased synthesis of corticosterone in the adrenal cortex.
\end{abstract}

The root of Panax ginseng has been used for thousands of years in Asian countries empirically as folk medicine. Its chemical, pharmacological and biochemical studies, however, were rather recently begun. From the root 11 ginsenosides as its saponin were isolated, and their chemical structures were identified (Nagai et al., 1971; Sanada et al., 1974a and b; Sanada and Shoji, 1978). Various pharmacological actions of ginseng saponins or isolated ginsenosides were reported (Takagi, 1974; Kaku et al., 1975). As for biochemical actions, we showed that ginseng saponin preparations or isolated ginsenosides stimulated RNA and protein synthesis in rat liver, and carbohydrate and lipid metabolism in rat liver and adipose tissue (Oura et al., 1971 ; Hiai et al., 1971; Oura et al., 1975; Yokozawa et al., 1976).

Petkov and Staneva (1963) showed that

Received November 20, 1978. an extract from Panax ginseng root increased urinary corticosteroid, and decreased acidophils in peripheral blood and adrenal cholesterol and ascorbic acid contents in rats, and they suggested that the ginseng extract stimulated adrenocortical function. Previously we reported that a ginseng saponin preparation increased adrenocortical cyclic AMP in intact rats, but not in hypophysectomized rats (Hiai et al., 1979). In this study we examined the effect of ginseng saponin on plasma ACTH and corticosterone in rats.

\section{Materials and Methods}

Male Wistar rats were fed on water and laboratory chow (CE-2, CLEA Japan Inc., Tokyo) freely, and maintained in a $24^{\circ} \mathrm{C}$ room with $12 \mathrm{hr}$ of artificial light (light phase, 0600 to $1800 \mathrm{hr}$ ). Rats weighing $130-150 \mathrm{~g}$ kept in these conditions for more than 5 days were decapitated with a guillotine to avoid 
stress-stimulated corticoid release in a next room immediately after transfer (within $15 \mathrm{sec}$ ) at 0900 $1000 \mathrm{hr}$. Trunk blood was received in a chilled tube containing heparin sodium salt, and plasma sample after centrifugation at $4^{\circ} \mathrm{C}$ was divided into several portions and then frozen and stored at $-20^{\circ} \mathrm{C}$.

Ginseng saponins used in this work were fractions 5 and 6 and ginsenosides $\mathrm{Rb}_{1}, \mathrm{Rb}_{2}, \mathrm{Rc}, \mathrm{Rd}$ and $\mathrm{Re}$, and they were prepared from Panax ginseng root as reported previously (Oura et al., 1975). Fractions 5 and 6 were purified mixtures of ginseng saponin containing ginsenosides $\mathrm{Rb}_{1}, \mathrm{Rb}_{2}, \mathrm{Rc}, \mathrm{Rc}_{2}$ (probably corresponds to $R_{3}$ ), $R d, R e$ and $R_{1}$ which have sapogenin moiety of dammarane group, protopanaxadiol or protopanaxatriol. Fractions 5 and 6 contained $42 \%$ and $45 \%$ of protopanaxadiol equivalent sapogenin (cf. Hiai et al., 1975). Glycyrrhizin and saikosaponin c (Kubota and Hinoh, 1968) have genin moiety of oleanane group, glycyrrhetinic acid and saikogenin $\mathrm{E}$, respectively, and these saponins were kindly supplied from Minophagen Pharmaceutical Co., Tokyo and Shionogi \& Co., Osaka, respectively. They were dissolved or suspended in pyrogen-free saline and used.

Frozen plasma sample was melted, centrifuged to remove small amounts of fibrous substance, and then the supernatant was used for the determination in duplicate. ACTH was determined by the radioimmunoassay method using the kit of Radiochemical Centre, Amersham, which consists of anti-human ACTH serum, standard human ACTH and ${ }^{125}$ I- $\alpha^{1-24}$. ACTH. Thus the immunoreactive ACTH values in this work are relative values for the true rat ACTH. Corticosterone was determined essentially according to the competitive protein binding method of Murphy (1967). Ethyl acetate was used for extraction of corticosterone. Serum from betamethasone-treated man was used for the corticoid binding protein. Standard corticosterone and ${ }^{3} \mathrm{H}$-corticosterone (45 $\mathrm{Ci} / \mathrm{mm}$ ) were from Merck and Radiochemical Centre, respectively. Addition of ginseng saponin, dexamethasone, glycyrrhizin or sakiosaponin $c$ to the assay system for corticosterone did not affect the determination.

\section{Results}

Increase in plasma ACTH and corticosterone

Kinetic pattern of plasma ACTH concentration was determined when fraction 5 or 6 saponin preparation $(7 \mathrm{mg} / 100 \mathrm{~g})$ was administered to rats intraperitoneally. ACTH was assayed in duplicate with pooled plasma of each group of rats. Fig. 1 shows that plasma ACTH increased $10 \mathrm{~min}$, de-

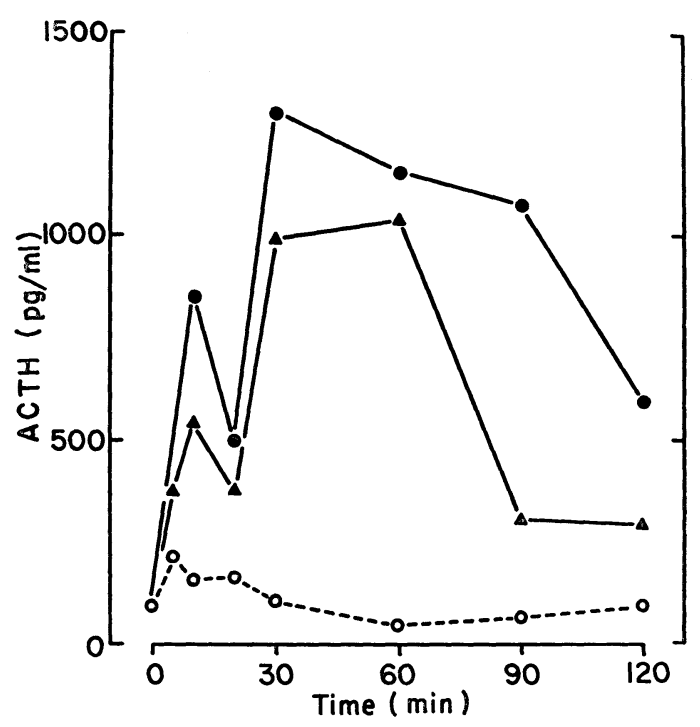

Fig. 1. Effect of ginseng saponin on plasma ACTH. Rats were received fraction 5 or $6(7 \mathrm{mg} / 100 \mathrm{~g}$, i.p.) or saline $(0.5 \mathrm{ml})$. ACTH was determined with pooled plasma of 3 or 4 rats in duplicate. Values at 0 time are for plasma from untreated 6 rats. Animals were sacrificed between 0900 and $1000 \mathrm{hr}$. O, $\Delta$ Fraction 5, 6; O saline-treated control.

creased $20 \mathrm{~min}$ and then clearly increased $30 \mathrm{~min}$ after the treatment with fraction 5 or 6. Plasma ACTH concentration remained high for 30 or $60 \mathrm{~min}$, and then rapidly decreased $90 \mathrm{~min}$ (fraction 6) or $120 \mathrm{~min}$ (fraction 5) after the treatment. The reason for a drop at $20 \mathrm{~min}$ after the treatment is not clear at present. In saline-treated control rats, the increase in ACTH was also observed, and it was small and transient (Fig. 1).

With plasma of an individual rat, ACTH and corticosterone concentrations were determined in duplicate. As shown in Table 1, plasma ACTH concentration increased significantly 30,60 and $90 \mathrm{~min}$ after the treatment with fraction $5(\mathrm{p}<0.001, \mathrm{p}<0.01$, $\mathrm{p}<0.01)$. The increase in plasma ACTH 
Table 1. Effect of ginseng saponin on plasma ACTH and corticosterone.

\begin{tabular}{|c|c|c|c|c|c|c|}
\hline \multirow{2}{*}{$\begin{array}{l}\text { Time after } \\
\text { treatment } \\
(\mathrm{min})\end{array}$} & \multicolumn{2}{|c|}{ ACTH $(\mathrm{pg} / \mathrm{ml})$} & \multicolumn{4}{|c|}{ Corticosterone $(\mu \mathrm{g} / \mathrm{d} l)$} \\
\hline & $\begin{array}{l}\text { Saline* } \\
\text { treated }\end{array}$ & $\begin{array}{l}\text { Saponini** } \\
\text { treated }\end{array}$ & $\mathbf{P}$ & $\begin{array}{l}\text { Saline* } \\
\text { treated }\end{array}$ & $\begin{array}{l}\text { Saponin** } \\
\text { treated }\end{array}$ & $\mathbf{P}$ \\
\hline $0 * * *$ & $93 \pm 21$ & - & - & $4.6 \pm 2.1$ & - & - \\
\hline 30 & $96 \pm 34$ & $1250 \pm 50$ & $<0.001$ & $12 \pm 8$ & $48 \pm 3$ & $<0.02$ \\
\hline 60 & $48 \pm 6$ & $1430 \pm 280$ & $<0.01$ & $0.9 \pm 0.6$ & $52 \pm 5$ & $<0.001$ \\
\hline 90 & $133 \pm 27$ & $750 \pm 110$ & $<0.01$ & $6.8 \pm 3.2$ & $51 \pm 5$ & $<0.01$ \\
\hline
\end{tabular}

Animals were sacrificed between 0900 and $1000 \mathrm{hr}$. Data were expressed as means \pm S.E. for 3 rats.

$* 0.5 \mathrm{ml}$ of saline; $\quad * *$ fraction $5,7 \mathrm{mg} / 100 \mathrm{~g}$, i.p.; $\quad * * *$ taken from Fig. 1, 6 non-treated rats.

was almost parallel to that in plasma corticosterone, but $90 \mathrm{~min}$ after the treatment plasma ACTH was one half of a maximum level while plasma corticosterone was still high.

\section{Dose-response relation}

Fig. 2 shows a dose-response relation between fraction 6 and plasma corticosterone concentration $30 \mathrm{~min}$ after the intraperitoneal administration to rats "gentled" by daily manual handling (for 4 days, twice a day in the morning and evening). Fraction 6 induced an increase in plasma corticosterone concentration in a dose-dependent manner in doses of 0.5 to $4 \mathrm{mg} / 100 \mathrm{~g}$. Fraction 6 in doses of $4 \mathrm{mg}$ and over seemed to show a maximum response in plasma corticosterone concentration, and the half maximum was obtained in a dose of about $1.5 \mathrm{mg} / 100 \mathrm{~g}$. When 3.5 and $7 \mathrm{mg} / 100 \mathrm{~g}$ of fraction 6 were administered, the maximum level of corticosterone was kept for about 0.5 and $1.5 \mathrm{hr}$, respectively. Therefore, a large dose of ginseng saponin seemed to lengthen the duration of the maximum level of plasma corticosterone and to increase in total amount of secreted corticosterone. Fraction 5 saponin in a dose of $3.5,7$ or $14 \mathrm{mg} / 100 \mathrm{~g}$ also showed a maximum response in plasma corticosterone as fraction 6 at doses of $4 \mathrm{mg} / 100 \mathrm{~g}$ and over did.

\section{Effect of isolated triterpenoidal saponin} of ginseng and other

Several ginsenosides isolated from fraction 5 or 6 were intraperitoneally adminis-

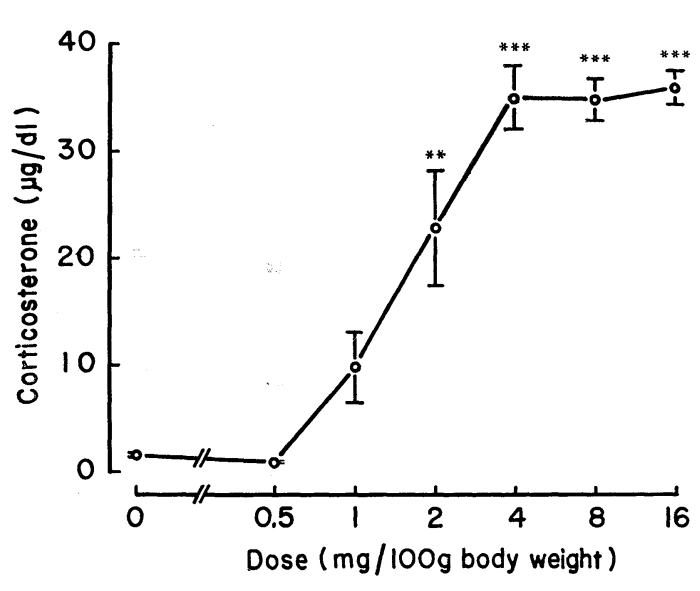

Fig. 2. Dose-response relation between graded doses of fraction 6 and plasma corticosterone in "gentled" rats. Animals were sacrificed between 0900 and $1000 \mathrm{hr}, 30 \mathrm{~min}$ after the treatment. Data were expressed as means \pm S.E. for 6 rats. ** $\mathrm{p}<0.01, \quad * * * \mathrm{p}<0.001$.

Table 2. Effect of isolated ginsenosides on plasma corticosterone.

\begin{tabular}{|c|c|c|c|}
\hline $\begin{array}{l}\text { Treatment } \\
(\mathrm{mg} / 100 \mathrm{~g})\end{array}$ & $\begin{array}{c}\text { No. of } \\
\text { rats }\end{array}$ & $\begin{array}{l}\text { Corticosterone } \\
(\mu \mathrm{g} / \mathrm{d} l)\end{array}$ & $\mathbf{P}$ \\
\hline Saline & 8 & $3.9 \pm 0.6$ & - \\
\hline $\mathrm{Rb}_{1} 7$ & 5 & $41 \pm 4$ & $<0.001$ \\
\hline 3.5 & 10 & $19 \pm 5$ & $<0.02$ \\
\hline $\mathrm{Rb}_{2} 7$ & 5 & $31 \pm 6$ & $<0.001$ \\
\hline 3.5 & 5 & $31 \pm 9$ & $<0.01$ \\
\hline Rc 3.5 & 4 & $50 \pm 3$ & $<0.001$ \\
\hline $\mathrm{Rd} \quad 3.5$ & 4 & $38 \pm 12$ & $<0.01$ \\
\hline $\operatorname{Re} 3.5$ & 5 & $16 \pm 6$ & $<0.05$ \\
\hline
\end{tabular}

Animals were sacrificed $0900-1000 \mathrm{hr}, 30 \mathrm{~min}$ after the treatment. Data were expressed as means \pm S.E. 
tered to rats, and plasma corticosterone was determined $30 \mathrm{~min}$ after the treatment. As shown in Table 2, all ginsenosides (genuine sapogenin of ginsenosides $R b_{1}, R b_{2}, R c$ and $\mathrm{Rd}$, protopanaxadiol; genuine sapogenin of ginsenoside $\mathrm{Re}$, protopanaxatriol) increased significantly plasma corticosterone in a dose of $3.5 \mathrm{mg} / 100 \mathrm{~g}$. Among these ginsenosides, $\mathrm{Rb}_{2}$ and $\mathrm{Rd}$ seemed more affective than $R b_{1}$ and $R e$.

Effects of glycyrrhizin and sakiosaponin c, triterpenoidal saponin found in the root of Glycyrrhiza glabra L. (licorice, Kanzo in Japanese) and Bupleurum falcatum L. (Mishima-saiko in Japanese) on plasma corticosterone were determined $30 \mathrm{~min}$ after the treatment with a dose of $10 \mathrm{mg} / 100 \mathrm{~g}$. Plasma corticosterone was $7.3 \pm 1.3 \mu \mathrm{g} / \mathrm{d} l$ $(\mathrm{n}=6)$ for glycyrrhizin and $4.4 \pm 0.8 \mu \mathrm{g} / \mathrm{d} l$ $(\mathrm{n}=5)$ for saikosaponin $\mathrm{c}$. Both values were not significant $v s$ the saline-treated control, $4.5 \pm 1.0 \mu \mathrm{g} / \mathrm{d} l(\mathrm{n}=12)$.

\section{Effect of dexamethasone}

Dexamethasone depresses secretion of both ACTH and corticosteroid (Bohus and Strashimirov, 1970). Rats were pretreated with dexamethasone ( $35 \mu \mathrm{g} / 100 \mathrm{~g}$, i.p.) $2.5 \mathrm{hr}$ before the ginseng or saline administration, and plasma corticosterone was determined. As shown in Table 3, ginseng saponin-

Table 3. Effect of dexamethasone pretreatment on ginseng saponin-induced increase in plasma corticosterone.

\begin{tabular}{lccc}
\hline \hline \multirow{2}{*}{ Pretreatment } & \multicolumn{3}{c}{$\begin{array}{c}\text { Corticosterone } \\
(\mu \mathrm{g} / \mathrm{d} l)\end{array}$} \\
& $\begin{array}{c}\text { Saline } \\
\text { treated }\end{array}$ & $\begin{array}{c}\text { Saponin } \\
\text { treated }\end{array}$ & P \\
\hline Saline & $5.6 \pm 1.2$ & $51 \pm 8$ & $<0.001$ \\
Dexamethasone & $0.2 \pm 0.1$ & $10 \pm 4$ & $<0.05$ \\
P & $<0.01$ & $<0.01$ & - \\
\hline
\end{tabular}

Dexamethasone $(35 \mu \mathrm{g} / 100 \mathrm{~g}$, i.p.) or saline $(0.5 \mathrm{ml})$ was administered to rats $2.5 \mathrm{hr}$. before the second treatment. As the second treatment, fraction 6 $(7 \mathrm{mg} / 100 \mathrm{~g}$, i.p.) or saline $(0.5 \mathrm{ml})$ was administered $30 \mathrm{~min}$ before decapitation. Animals were sacrificed between 0900 and $1000 \mathrm{hr}$. Data were expressed as means \pm S.E. for 5 rats. induced level of plasma corticosterone in dexamethasone-treated rats was clearly depressed from the ginseng-induced level of corticosterone without dexamethasone pretreatment $(10 \mu \mathrm{g} / \mathrm{d} l$ vs $51 \mu \mathrm{g} / \mathrm{d} l)$. This result shows that the stimulating effect of ginseng saponin on plasma corticosterone and ACTH was involved with the blocking action of dexamethasone.

\section{Discussion}

In the preceding work we showed that a ginseng saponin preparation fraction 5 increased adrenal cAMP in intact rats, but not in hypophysectomized rats (Hiai et al., 1979). From these results, the ginseng preparation was expected to increase ACTH secretion and to stimulate the pituitary rather directly and the adrenal cortex indirectly. In the present work, as was expected, we found that ginseng saponin significantly increased plasma ACTH, while it increased plasma corticosterone in a parallel kinetic pattern. Thus, the ginseng-induced increase in plasma ACTH verified that the ginsenginduced increase in plasma corticosterone was due to the stimulation of corticosterone synthesis in the adrenals and corticosterone secretion from the adrenals, and not to the reduction in metabolism of corticoid (as action of glycyrrhizin, Kumagai et al., 1957) and in excretion of corticosterone into urine, and that the ginseng-induced increase in adrenal cAMP was due to the ginsenginduced increase in ACTH secretion.

All the ginsenosides whose sugar moieties are different from each other stimulated corticosterone secretion, so the stimulation of corticosterone (and ACTH) secretion by ginseng saponin may be mainly due to their sapogenin moiety, protopanaxadiol or protopanaxatriol. Glycyrrhizin and saikosaponin c whose sapogenins are different from those of ginsenosides were inactive in a dose of $10 \mathrm{mg} / 100 \mathrm{~g}$. Therefore, it was suggested that the stimulation of corticosterone sec- 
retion was not an attribute of triterpenoidal saponin.

Dexamethasone blocks ACTH and so corticoid secretion, and the site of the blocking action is known to be hypophysis and hypothalamus (Bohus and Strashimirov, 1970). The present result that the ginseng saponin-induced increase in plasma corticosterone (and ACTH) was blocked by dexamethasone indicates that ginseng saponin acted on the hypophysis and/or hypothalamus primarily, but not on the adrenocortex. Whether ginseng saponin administered intraperitoneally per se acted directly on the hypothalamus and/or hypophysis via blood circulation, or whether the saponin affected peripheral activity which stimulated the hypothalamus and/or hypophysis via input humoral or neural channel, remains to be elucidated.

Our conclusions, therefore, are (a) ginseng acted on the hypothalamus and/or hypophysis to secrete ACTH primarily but not on the adrenal cortex directly, (b) ginseng increased adrenocortical cAMP by the induction of ACTH secretion, and (c) ginseng stimulated corticosteroid synthesis in the adrenocortex and secretion from the adrenocortex by the increased adrenal cAMP. The present results support the findings by Petkov and Staneva (1963) and proved their suggestion. Furthermore, we showed that saponin as a constituent of Panax ginseng root stimulated the adrenocortical function.

Some of the known biochemical and pharmacological actions of ginseng saponin as well as ginseng extract may be ascribed partly to the actions of ACTH and corticosteroid secreted by ginseng saponin. Kaku et al. (1975) reported that the repeated administration of ginsenoside $\mathrm{Rf}, \mathrm{Re}$ or $\mathrm{Rd}$ caused facilitation of the conditioned avoidance response. Petkov (1978) established that an extract of ginseng improved the indices for learning and memory retention in rats. On the other hand, it has been re- ported recently that $\mathrm{ACTH}$ and the related peptide enhance the retention of learned response in rats (Reith et al., 1977). Therefore, we may suggest that the effect of ginseng saponin and extract on the learning behavior may be due to the increase in ACTH secretion.

\section{Acknowledgement}

We wish to thank Professor A. Kumagai of Chiba University for his advice and encouragement; and Mr. T. Nagasawa for his technical assistance. This work was supported in part by the Grant-in-Aid for Scientific Research from the Ministry of Education, Science and Culture (No. 144074).

\section{References}

Bohus, D. and D. Strashimirov (1970). Neuroendocrinology 6, 197.

Hiai, S., H. Oura, Y. Odaka and T. Nakajima (1975). Planta Medica 28, 363.

Hiai, S., H. Oura, K. Tsukada and Y. Hirai (1971). Chem. Pharm. Bull. 19, 1656.

Hiai, S., S. Sasaki and H. Oura (1979). Planta Medica 37, 15.

Kaku, T., T. Miyata, T. Uruno, I. Sako and A. Kinoshita (1975). Arzneim.-Forsch. 25, 539.

Kubota, T. and H. Hinoh (1968). Tetrahedron Lett. 303.

Kumagai, A., S. Yano, M. Otomo and K. Takeuchi (1957). Endocrinol. Japon. 4, 17.

Murphy, B. E. P. (1967). J. Clin. Endocrinol. 27, 973. Nagai, Y., O. Tanaka and S. Shibata (1971). Tetrahedron 27, 881.

Oura, H., S. Hiai, S. Nakashima and K. Tsukada (1971). Chem. Pharm. Bull. 19, 453.

Oura, H., S. Hiai, Y. Odaka and T. Yokozawa (1975). J. Biochem. 77, 1057.

Petkov, V. (1978). Arzneim.-Forsch. 28, 388.

Petkov, V. and D. Staneva (1963). Arzneim.-Forsch. 13, 1078.

Reith, M. E. A., P. Schotman, W. H. Gipsen and D. DeWied (1977). Trends Biochem. Sci. 2, 56.

Sanada, S., N. Kondo, J. Shoji, O. Tanaka and S. Shibata (1974a). Chem. Pharm. Bull. 22, 421.

Sanada, S., N. Kondo, J. Shoji, O. Tanaka and S. Shibata (1974b). Chem. Pharm. Bull. 22, 2407.

Sanada, S. and J. Shoji (1978). Chem. Pharm. Bull. 26, 1694.

Takagi, K. Proc. Intern. Ginseng Symp. Korean Office of Monopoly, Seoul, p. 119 (1974).

Yokozawa, T., K. Kanai, M. Takefuji and H. Oura (1976). Chem. Pharm. Bull. 24, 3202. 